\title{
A Collaborative Business Model for Imperfect Process with Setup Cost and Lead Time Reductions
}

\author{
Chien-Chung Lo \\ Department of Business Management, National United University, Miaoli, Chinese Taipei \\ Email: low@ nuu.edu.tw
}

Received October 2013

\begin{abstract}
This paper develops a collaborative business model for imperfect process with setup cost and lead time reductions. We propose a simple solution procedure to derive the optimal order quantity, lead time, delivery frequency and setup cost. Shortage during the lead time is assumed to be partially backordered. Numerical examples are carried out to show how the proposed model can result in a substantial cost savings over the traditional model.
\end{abstract}

Keywords: Collaborative Model; Imperfect Process; Lead Time Reduction; Setup Cost Reduction

\section{Introduction}

Strategic business alliance is a formalized type of collaborative relationship between a vendor and a buyer in a supply chain. It involves commitment to long-term cooperation, shared benefits, joint problem solving and information sharing. This close partnership will ultimately improve product quality and reduce inventory cost and lead time of the supply chain.

(Goyal, 1976) was one of the first authors to develop an integrated inventory model for a single supplier-single customer problem. The joint vendor-buyer optimization was later reinforced by (Banerjee, 1986; Goyal, 1988). (Lu, 1995; Hill 1997) presented a cooperative multiple deliveries policy. (Ha \& Kim, 2003) considered a simple JIT single-setup multi-delivery model and a single-setup single-delivery (SSSD) model. (Yang \& Wee, 2000) considered an integration issue in an integrated deteriorating model. However, the quality related issues and the benefits of the setup cost and lead time reduction were not addressed in these integrated models.

Setup cost reduction is one of the important production activities in an integrated inventory control. In practice, setup cost can be reduced through worker training, procedural changes and specialized equipment acquisition. (Porteus, 1986) studied the impact of investing in reducing setup cost by considering the discounted model. (Affisco, Paknejad, \& Nasri, 1988, 2002) addressed the joint optimization cost of the vendor and the buyer. They showed that by investing in setup cost reduction of the vendor, a significant saving in joint total cost can be achieved. (Nasri, Paknejad, \& Affisco, 1991) extended Banerjee's model to investigate the impact of investing in setup cost and ordering cost reductions simultaneously. Their results indicated that both the vendor and the buyer can realize significant savings.

Lead time reduction is another important production activity in an integrated inventory control. Lead time consists of order preparation, order transmittal, order processing and assembly, additional stock acquisition time and delivery time (Ballou, 2004). In most cases, lead time can be shortened with an added crashing cost. Recently, (Ouyang, Yeh, \& Wu, 1996) extended the $(Q, r)$ model by (Ben-Daya \& Raouf, 1994) to consider the lead time effect and incorporate the partial backordering into the inventory model. (Hariga, 1999) studied the relationship between lot size and lead time in the process time aspect. (Pan \& Yang, 2002) presented an integrated supplier-purchaser model with controllable lead time. The model has a substantial cost saving when lead time is controllable. (Chen, Chang, \& Ouyang, 2001) presented a continuous review inventory model when ordering cost is dependent on lead time. (Ben-Daya \& Hariga, 2003) developed a continuous review inventory model where lead time is considered as a controllable variable. Lead time is decomposed into all its components: set-uptime, processing time and non-productive time. Later, (Ouyang, Wu, \& Ho, 2004) extended Pan and Yang's model by allowing shortages.

In a real system, due to the imperfect production process of the vendor and the damages during the transportation process from the vendor to the buyer, goods received by the buyer may contain some percentage of defectives. Recently, (Salameh \& Jaber, 2000) examined a joint EOQ lot sizing and inspection policy with imperfect quality. They assumed $100 \%$ screening and all poor-quality items were sold at the end of the screening process. (Goyal, Huang, \& Chen, 2003; Huang, 2004) extended Salameh and Jaber's model and proposed an integrated vendor-buyer cooperative inventory model for items with imperfect quality. (Parachristos \& Konstantaras, 2006) pointed out some drawback in Salameh and Jaber's model regarding ensuring no shortage occurrence. They extended the model by Salameh and Jaber to consider withdraw at the end of the planning horizon, and consider different inspection process with Bernoulli random variable and sufficient condition to prevent shortage. (Chung \& Huang 2006) modified two assumptions of the classical EOQ model to reflect the real-life situations. Their study incorporated the model by (Salameh \& Jaber, 2000) to consider a retailer's production/inventory model with imperfect quality and permissible delay in payments.

In our integrated business model, lead time demand is considered to be normally distributed. We derive the joint total expected cost function for the partners and propose a simple algorithm procedure to derive the optimal integrated business model policy. Finally, numerical examples are carried out to show how the proposed model can result in a substantial cost savings 
over the traditional model.

\section{Notation and Assumptions}

The notation used in our model is shown as follows:

$D$ : average demand per year for the buyer

$P$ : production rate of the vendor

$A$ : per ordering cost for the buyer

$A_{0}$ : original ordering cost

$S$ : per setup cost for the vendor (decision variable)

$S_{0}$ : original setup cost

$I(S)$ : capital investment in reducing the vendor's setup cost;

$$
I(S)=C_{S} \ln \left(S_{0} / S\right) \text {, for } 0<S \leq S_{0},
$$

where the parameter $C_{S}=1 / \theta$ and $\theta$ denotes the percentage decrease in $S$ per dollar increase in $I(S)$

$\alpha_{S}$ : the fractional cost of the vendor's capital investment

$C_{b}$ : unit purchase cost paid by the buyer

$C_{v}$ : unit production cost paid by the vendor

$r_{b}$ : inventory carrying cost percentage per year per dollar for the buyer

$r_{v}$ : inventory carrying cost percentage per year per dollar for the vendor

$\pi$ : stock-out cost per unit short for the buyer

$\pi_{0}$ : marginal profit per unit for the buyer

$\beta$ : fraction of the shortage that will be backordered, $\beta \in[0,1]$

$\gamma$ : screening rate for the buyer

$t$ : screening period for each arrival lot

$u$ : screening cost per unit for the buyer

$v$ : warranty cost of defective items per unit for the vendor

$R$ : reorder point of the buyer (decision variable)

$Q$ : order quantity of the buyer (decision variable)

$L$ : length of lead time for the buyer (decision variable)

$L_{0}$ : original length of lead time

$m$ : number of lots in which the items are delivered from the vendor to the buyer in one production cycle (decision variable)

$X$ : lead time demand which has a cumulative distribution function (c.d.f.) $F$ with finite mean $D L$ and standard deviation $\sigma \sqrt{L}$, where $\sigma$ denotes the standard deviation of demand per unit time.

$Y$ : percentage of defective items in $Q$

$f(y)$ : probability density function of $Y$

$\phi(\cdot)$ : standard normal probability density function

$\Phi(\cdot)$ : standard normal cumulative distribution function

$E(\cdot)$ : expected value

$T C_{b}$ : total expected annual cost for the buyer

$T C_{v}$ : total expected annual cost for the vendor

JTC: joint total expected cost including $T C_{b}$ and $T C_{v}$

It is assumed that the buyer adopts a continuous review inventory policy where lead time can be reduced by a crashing cost. The vendor may also invest in setup cost reduction. The imperfect production process of the vendor results in random defective items. As a result, an order received by the buyer has a certain percentage of defective items. Since $100 \%$ screening process is used, all the defective items are screened out and discarded. Other assumptions for our model are:

- $R=D L+k \sigma \sqrt{L}$, where $S S=k \sigma \sqrt{L}$ and $k$ is the safety factor.

- Shortages are partially backordered.

- The lead time $L$ has n mutually independent components. The $\mathrm{i}^{\text {th }}$ component has a minimum duration $\mathrm{a}_{\mathrm{i}}$ and normal duration $b_{i}$, and a crashing cost $c_{i}$ per unit time. The components can be rearranged such that $c_{1} \leq c_{2} \leq \cdots \leq c_{n}$. The components are crashed from the least crashing cost per unit time.

- The lead time and ordering cost reductions have the following relationship:

$$
\left(A_{0}-A\right) / A_{0}=\tau \ln \left(L / L_{0}\right)
$$

where $\tau(<0)$ is constant scaling parameter for the logarithmic relationship between percentages in lead time reductions and ordering cost.

- $Y$ and the buyer's demand are independent random variables.

- The extra costs incurred by the vendor will be fully transferred to the buyer if shortened lead time is requested.

- The number of good units is equal or greater than the demand during the screening period.

\section{Model Formulation}

The shortage quantity at the end of the buyer's replenishment cycle is $(X-R)^{+}$and the order cycle length of the buyer is (1$Y) Q / D$, where $X$ and $Y$ are assumed to be independent random variables. Hence, the expected annual stock-out cost for the buyer is.

$$
\begin{aligned}
& {\left[\pi+\pi_{0}(1-\beta)\right] E\left[\frac{D(X-R)^{+}}{(1-Y) Q}\right] } \\
= & E\left(\frac{1}{1-Y}\right) \frac{D}{Q}\left[\pi+\pi_{0}(1-\beta)\right] E(X-R)^{+}
\end{aligned}
$$

The net inventory level of the good items at the epoch before and after receipt of an order is $R-D L+(1-\beta) E(X-R)^{+}$and $[1-E(Y)] Q+R-\mathrm{D} L+(1-\beta) E(X-R)^{+}$respectively. The average inventory of good items is $[1-E(Y)] Q / 2+R-D L+(1$ $-\beta) E(X-R)^{+}$. Since the defective items are discarded after the screening process, the buyer's expected defective item inventory is $E\{t Q Y /[(1-Y) Q / D]\}=E[Y /(1-Y)] Q D / \gamma$. The total expected inventory carrying cost per year for the buyer is

$$
r_{b} C_{b}\left\{\begin{array}{l}
E\left(\frac{Y}{1-Y}\right) \frac{Q D}{\gamma}+\frac{[1-E(Y)] Q}{2} \\
+(R-D L)+(1-\beta) E(X-R)^{+}
\end{array}\right\}
$$

Let $L_{i}$ be the length of lead time with components $1,2, \ldots, i$ crashed to their minimum duration, then $\mathrm{L}_{\mathrm{i}}$ can be expressed as

$$
\begin{aligned}
& L_{i}=L_{0}-\sum_{j=1}^{i}\left(b_{j}-a_{j}\right) \\
= & \sum_{j=1}^{n} b_{j}-\sum_{j=1}^{i}\left(b_{j}-a_{j}\right), \quad i=1,2, \ldots, n
\end{aligned}
$$

The lead time crashing cost $C(L)$ per cycle for a given $L \in$ $\left[L_{i}, L_{i-1}\right]$ is

$$
C(L)=c_{i}\left(L_{i-1}-L\right)+\sum_{j=1}^{i-1} c_{j}\left(b_{j}-a_{j}\right)
$$

Therefore, the expected lead time crashing cost per year for the buyer is $E\{C(L) /[(1-Y) Q / D]\}=E[1 /(1-Y)] D C(L) / Q$. From assumption (4), the lead time $\mathrm{L}$ and ordering cost $\mathrm{A}$ have a relationship:

$$
\left(A_{0}-A\right) / A_{0}=\tau \ln \left(L / L_{0}\right)
$$

Equation (5) can be rewritten as 


$$
A(L)=d+e \ln (L)
$$

where $d=A_{0}+\tau A_{0} \ln \left(L_{0}\right)$ and $e=-\tau A_{0}>0$.

Summarizing the ordering cost, the screening cost, the inventory carrying cost, the stockout cost and the lead time crashing cost, the total expected annual cost of the buyer is

$$
\begin{aligned}
& T C_{b}(Q, L, R)=E\left(\frac{1}{1-Y}\right) \frac{D}{Q}[d+e \ln (L)] \\
& +E\left(\frac{1}{1-Y}\right) u D+r_{b} C_{b}\left\{E\left(\frac{Y}{1-Y}\right) \frac{Q D}{\gamma}\right. \\
& \left.+\frac{[1-E(Y)] Q}{2}+(R-D L)+(1-\beta) E(X-R)^{+}\right\} \\
& +E\left(\frac{1}{1-Y}\right) \frac{D}{Q}\left[\pi+(1-\beta) \pi_{0}\right] E(X-R)^{+} \\
& +E\left(\frac{1}{1-Y}\right) \frac{D}{Q} C(L)
\end{aligned}
$$

The total expected annual cost of the vendor includes the setup cost, the warranty cost, the inventory carrying cost and the investment in setup cost reduction. One has

$$
\begin{aligned}
& T C_{v}(Q, m, S)=E\left(\frac{1}{1-Y}\right) \frac{D S}{m Q}+E\left(\frac{Y}{1-Y}\right) v D \\
& +r_{v} C_{v} \frac{Q}{2}\left\{m\left[1-E\left(\frac{1}{1-Y}\right) \frac{D}{P}\right]-1+E\left(\frac{1}{1-Y}\right) \frac{2 D}{P}\right\} \\
& +\alpha_{S} C_{S} \ln \left(\frac{S_{0}}{S}\right), \quad \text { for } 0<S \leq S_{0}
\end{aligned}
$$

The joint total expected annual cost JTC for the vendor and the buyer is the sum of $T C_{p}$ and $T C_{b}$. One has

$$
T C(Q, L, R, m, S)=T C_{b}(Q, L, R)+T C_{v}(Q, m, S)
$$

After some algebra manipulations on (9) and using $\mathrm{M}$ instead of $E[1 /(1-Y)]$, the problem is formulated as

Minimize $\operatorname{JTC}(Q, L, R, m, S)$

$$
\begin{aligned}
& \frac{D M}{Q}\left\{(d+e \ln (L))+\frac{S}{m}+\left[\pi+(1-\beta) \pi_{0}\right] E(X-R)^{+}+C(L)\right\} \\
& +(v+u) D M-v D+r_{b} C_{b}\left[(R-D L)+(1-\beta) E(X-R)^{+}\right] \\
& +r_{b} C_{b} \frac{Q}{2}\left[\frac{2 D M}{\gamma}-\frac{2 D}{\gamma}+(1-E(Y))\right] \\
& +r_{v} C_{v} \frac{Q}{2}\left[m\left(1-\frac{D M}{P}\right)-1+\frac{2 D M}{P}\right]+\alpha_{S} C_{S} \ln \left(\frac{S_{0}}{S}\right)
\end{aligned}
$$

Subject to $0<S \leq S_{0}$

\section{The Optimal Solution}

When the lead time demand $X$ is assumed to follow a normal distribution, the expected shortage quantity $E(X-R)^{+}$can be expressed as

$$
\begin{aligned}
& E(X-R)^{+}=\int_{R}^{\infty}(x-R) d F(x) \\
& =\int_{k}^{\infty} \sigma \sqrt{L}(z-k) d \Phi_{z}(z) d z=\sigma \sqrt{L} \varphi(k)>0
\end{aligned}
$$

where $\phi(k)=\varphi(k)-k[1-\Phi(k)]$

Substituting (11) and $R-D L=k \sigma \sqrt{L}$ into (10) and using the safety factor $k$ as a decision variable instead of $R,(10)$ is transformed to

Minimize $\operatorname{JTC}(Q, L, R, m, S)$

$$
\begin{aligned}
& \frac{D M}{Q}\left\{(d+e \ln (L))+\frac{S}{m}+\left[\pi+(1-\beta) \pi_{0}\right] \sigma \sqrt{L} \varphi(k)+C(L)\right\} \\
& +(v+u) D M-v D+r_{b} C_{b}[k+(1-\beta) \varphi(\mathrm{k})] \sigma \sqrt{L} \\
& +r_{b} C_{b} \frac{Q}{2}\left[\frac{2 D M}{\gamma}-\frac{2 D}{\gamma}+(1-E(Y))\right] \\
& +r_{v} C_{v} \frac{Q}{2}\left[m\left(1-\frac{D M}{P}\right)-1+\frac{2 D M}{P}\right]+\alpha_{S} C_{S} \ln \left(\frac{S_{0}}{S}\right)
\end{aligned}
$$

Subject to $0<S \leq S_{0}$

To solve the non-linear integer programming problem in (12), we temporarily ignore the constraint $0<S \leq S_{0}$. Taking the partial derivatives of $\operatorname{JTC}(Q, L, k, m, S)$ with respect to $L \in$ $\left[L_{i}, L_{i-1}\right]$, one has

$$
\begin{aligned}
& \frac{\partial J T C(Q, L, k, m, S)}{\partial L}=\frac{D M}{Q}\left(\frac{e}{L}-c_{i}\right)+\frac{r_{b} C_{b}}{2} k \sigma L^{-1 / 2} \\
& +\frac{1}{2}\left\{r_{b} C_{b}(1-\beta)+\frac{D M}{Q}\left[\pi+(1-\beta) \pi_{0}\right]\right\} \sigma L^{-1 / 2} \varphi(k)
\end{aligned}
$$

and

$$
\begin{aligned}
& \frac{\partial^{2} \operatorname{JTC}(Q, L, k, m, S)}{\partial L^{2}}=-\frac{D M}{Q} \frac{e}{L^{2}}-\frac{r_{b} C_{b}}{4} k \sigma L^{-3 / 2} \\
& -\frac{1}{4}\left\{r_{b} C_{b}(1-\beta)+\frac{D M}{Q}\left[\pi+(1-\beta) \pi_{0}\right]\right\} \sigma L^{-3 / 2} \varphi(k)<0
\end{aligned}
$$

Therefore, $\operatorname{JTC}(Q, L, k, m, S)$ is concave in $L \in\left[L_{i}, L_{i-1}\right]$ and the minimum expected joint total cost will occur at the end points of the interval $\left[L_{i}, L_{i-1}\right]$.

On the other hand, for fixed $L \in\left[L_{i}, L_{i-1}\right]$ and integer m, the following results of $Q, k$, and $S$ can be derived as:

$$
\begin{gathered}
Q=\left\{\frac{2 D M\left[(d+e \ln (L))+\frac{S}{m}+\left[\pi+(1-\beta) \pi_{0}\right] \sigma \sqrt{L} \varphi(k)+C(L)\right]}{r_{b} C_{b}\left[\frac{2 D M}{\gamma}-\frac{2 D}{\gamma}+(1-E(Y))\right]+r_{v} C_{v}\left[m\left(1-\frac{D M}{P}\right)-1+\frac{2 D M}{P}\right]}\right\}^{1 / 2} \\
\Phi(k)=1-\frac{r_{b} C_{b} Q}{r_{b} C_{b} Q(1-\beta)+D M\left[\pi+(1-\beta) \pi_{0}\right]}
\end{gathered}
$$

and

$$
S=\frac{\alpha_{S} C_{S} m Q}{D M}
$$

It can be shown that for fixed $\mathrm{m}$ and $L \in\left[L_{i}, L_{i-1}\right]$, the Hessian matrix of $\operatorname{JTC}(Q, L, k, m, S)$ is positive-definite at point $\left(Q^{*}, k^{*}, S^{*}\right)$ and hence, $\operatorname{JTC}(Q, L, k, m, S)$ is convex for the optimal value $\left(Q^{*}, k^{*}, S^{*}\right)$.

Substituting (15) into (12), JTC $(Q, L, k, m, S)$ can be reduced to

$$
\begin{aligned}
& J T C(m)=\left\{2 D M\left[(d+e \ln (L))+\frac{S}{m}+\left[\pi+(1-\beta) \pi_{0}\right] \sigma \sqrt{L} \phi(k)+C(L)\right]\right. \\
& \left.\times\left[r_{b} C_{b}\left[\frac{2 D M}{\gamma}-\frac{2 D}{\gamma}+(1-E(Y))\right]+r_{v} C_{v}\left[m\left(1-\frac{D M}{P}\right)-1+\frac{2 D M}{P}\right]\right]\right\}^{1 / 2} \\
& +(v+u) D M-v D+r_{b} C_{b}[k+(1-\beta) \phi(k)] \sigma \sqrt{L}+\alpha_{S} C_{S} \ln \left(\frac{S_{0}}{S}\right)
\end{aligned}
$$


The optimal value of $m$ (denoted by $m^{*}$ ) can be obtained when

$$
\operatorname{JTC}\left(m^{*}-1\right) \geq \operatorname{JTC}\left(m^{*}\right) \leq \operatorname{JTC}\left(m^{*}+1\right)
$$

We then develop the following algorithm to find the optimal value of $\mathrm{m}, Q, k, L$ and $S$.

\section{Algorithm 1}

Step 1. Set $m=1$.

Step 2. For each $L_{i}, i=0,1, \ldots, n$ performs i) to vii).

i) Start with $S_{\mathrm{i}}=S_{0}$ and $k_{i}=0$.

ii) Check the standard normal table to determine $\phi\left(k_{i}\right)$ and $\Phi\left(k_{i}\right)$.

iii) Use $\mathrm{k}_{\mathrm{i}}, \phi\left(k_{i}\right)$ and $\Phi\left(k_{i}\right)$ to compute

$\varphi(k)=\phi(k)-k[1-\Phi(k)]$.

iv) Substitute $S=S_{i}, m$ and $\varphi(k)=\varphi\left(k_{i}\right)$ into (15) to compute $Q_{i}$.

v) Substitute $Q=Q_{i}$ into (16) to determine $\Phi\left(k_{i}\right)$. Then check the standard normal table to determine $k_{i}$ and $\phi\left(k_{i}\right)$.

vi) Substitute $Q=Q_{i}$ and m into (17) to determine $S_{i}$.

vii) Repeat iii) to vi) until no change occurs in the values of $S_{i}$, $k_{i}$ and $Q_{i}$. Denote the solution by $\hat{S}_{i}, \hat{k}_{i}$ and $\hat{Q}_{i}$.

Step 3. Compare $\hat{S}_{i}$ and $S_{0}$.

i) If $\hat{S}_{i}<S_{0}$, then the solution found in Step 2 is optimal for a given $L_{i}$ and $m$. Denote the optimal solution by $S_{i}^{*}, k_{i}^{*}$ and $Q_{i}^{*}$.

ii) If $\hat{S}_{i} \geq S_{0}$, set $S_{i}^{*}=S_{0}$. The optimal value of $Q_{i}$ and $k_{i}$ can be determined by using proce-dure i) to vii) in Step 2 (It is noted that $S=S_{0}$ is fixed during this solution process).

Step 4. Compute $\operatorname{JTC}\left(Q_{i}^{*}, L_{i}, k_{i}^{*}, m, S_{i}^{*}\right)$ for $i=0,1, \ldots, n$.

Step 5. Set $\operatorname{JTC}\left(Q_{m}^{*}, L_{m}^{*}, k_{m}^{*}, m, S_{m}^{*}\right)=\min _{i=1,2, \ldots, \mathrm{n}}$ $\operatorname{JTC}\left(Q_{i}^{*}, L_{i}, k_{i}^{*} m, S_{i}^{*}\right)$. Then $\left(Q_{m}^{*}, L_{m}^{*}, k_{m}^{*}, S_{m}^{*}\right)$ is the optimal solution for fixed $m$.

Step 6. Set $m=m+1$ and repeat Step 2 to Step 5 to derive $\operatorname{JTC}\left(Q_{m}^{*}, L_{m}^{*}, k_{m}^{*}, m, S_{m}^{*}\right)$.

Step 7. If $\operatorname{JTC}\left(Q_{m}^{*}, L_{m}^{*}, k_{m}^{*}, m, S_{m}^{*}\right) \leq \operatorname{JTC}\left(Q_{m-1}{ }^{*}, L_{m-1}{ }^{*}\right.$, $\left.k_{m-1}{ }^{*}, m-1, S_{m-1}{ }^{*}\right)$, then go to Step 6, otherwise go to Step 8 .

Step 8. Set $\operatorname{JTC}\left(Q^{*}, L^{*}, k^{*}, m^{*}, S^{*}\right)=\operatorname{JTC}\left(Q_{m-1}{ }^{*}, L_{m-1}{ }^{*}, k_{m-1}{ }^{*}\right.$, $\left.m-1, S_{m-1}{ }^{*}\right)$, then $\left(Q^{*}, L^{*}, k^{*}, m^{*}, S^{*}\right)$ is the optimal solution.

\section{Numerical Example}

We consider an inventory system with the following data: $D$ = 600 units/year, $P=2000$ units/year, $\gamma=3000$ units/year, $A_{0}=$ \$200/order, $\mathrm{S}_{0}=\$ 1500 /$ setup, $C_{b}=\$ 100 /$ unit, $C_{v}=\$ 70 /$ unit, $\pi$
$=\$ 50 /$ unit, $\pi_{0}=\$ 150 /$ unit, $\beta=1.0, u=\$ 1 /$ unit, $v=\$ 100 /$ unit, $r_{b}$ $=r_{v}=.2, \sigma=7$ unit/week, $\alpha_{S}=.1, I(S)=10,000 \ln \left(S_{0} / S\right)$ and the three components of the lead time are shown in Table 1.

The percentage defectives $\mathrm{Y}$ of an order follow a uniform distribution with the following probability density function:

$$
f(y)= \begin{cases}25, & 0 \leq y \leq 0.04 \\ 0, & \text { otherwise }\end{cases}
$$

Therefore, one has

$$
E(Y)=\int_{0}^{0.04} 25 y d y=0.02
$$

and

$$
M=E\left(\frac{1}{1-Y}\right)=\int_{0}^{0.04} 25 \frac{1}{1-y} d y=1.02055
$$

The constant scaling parameter $\tau$ of the logarithmic relationship between lead time and ordering cost reductions has five different values. There are $0,-.2,-.5,-.8$ and -1 respectively.

When the lead time demand follows a normal distribution, Algorithm 1 procedure is applied to yield the results for various $\tau$ as shown in Table 2.

From this table, the optimal integrated policy for $\tau$ value can be found by comparing $\operatorname{JTC}\left(Q_{m}^{*}, L_{m}^{*}, k_{m}^{*}, m, S_{m}^{*}\right), i=0,1,2$, 3 , and the results are summarized in Table 3 . To illustrate the performance of our model, the result of the traditional model without setup cost, lead time and ordering cost reductions is listed in Table 3. From the results of Table 3, it is seen that the increasing absolute $\tau$ value results in higher frequency of deliveries, smaller lot size, shorter lead time, higher service level and lower total expected annual cost. From the cost comparison between our model and the traditional integrated model involving lead time reduction, we find that when the absolute $\tau$ value increases, larger total expected annual cost savings can be obtained.

(Goyal, 1976) assumed the joint total annual cost is equally allocated to the vendor and the buyer. For example, when $\tau=$ -.5 , the allocated buyer's total annual cost is $7477.2 \times 3046.3 /$ $(3046.3+4443.6)=3041.1$ and the allocated vendor's total annual cost is $7477.2 \times[1-3046.3 /(3046.3+4443.6)]=$ 4436.1. Equal saving allocation may not be the best policy. For an effective allocation, the integrated policy must work out the saving allocation to benefit both the vendor and the buyer. In Table 4, we compare the cost incurred by the players consider-

Table 1.

Lead time data.

\begin{tabular}{cccc}
\hline Lead Time Component & Normal Duration $b_{i}$ (days) & Minimum Duration $a_{i}($ days $)$ & Unit Crashing Cost $c_{i}(\$ /$ day $)$ \\
\hline 1 & 20 & 6 & 0.4 \\
2 & 20 & 6 & 1.2 \\
3 & 16 & 9 & 5.0 \\
\hline
\end{tabular}

Table 2.

The results for various $\tau$ using the solution procedures.

\begin{tabular}{cccccccccc}
\hline$\tau$ & $L^{*}$ & $m^{*}$ & $Q^{*}$ & $A\left(L^{*}\right)$ & $k^{*}\left(R^{*}\right)$ & $S^{*}$ & $S L$ & $J T C\left(Q^{*}, L^{*}, k^{*}, m^{*}, S^{*}\right)$ & ${\text { Savings }(\%)^{\mathrm{a}}}^{*}$ \\
\hline-.2 & 28 & 2 & 124 & 172.3 & $1.399(66)$ & 404.4 & .919 & 7728.1 & 9.58 \\
-.5 & 21 & 2 & 116 & 101.9 & $1.436(52)$ & 377.7 & .924 & 7477.2 & 12.51 \\
-.8 & 21 & 2 & 101 & 43.1 & $1.504(53)$ & 331.3 & .934 & 7145.4 & 16.39 \\
-1.0 & 21 & 3 & 74 & 3.8 & $1.661(55)$ & 362.3 & .952 & 6884.4 & 19.45 \\
Traditional model & 28 & 3 & 146 & 200.0 & $1.306(64)$ & 1500.0 & .904 & 8546.6 & - \\
\hline
\end{tabular}

${ }^{a}$ Savings is based on the traditional model involving lead time reduction only. 
Table 3.

Summary of the optimal integrated policy for various $\tau$.

\begin{tabular}{cccccccccc}
\hline$\tau$ & $m$ & $L_{m}^{*}$ & $C\left(L_{m}{ }^{*}\right)$ & $A\left(L_{m}^{*}\right)$ & $k_{m}^{*}\left(R_{m}^{*}\right)$ & $S_{m}^{*}$ & $Q_{m}^{*}$ & $S L^{\mathrm{a}}$ & $J T C\left(Q_{m}^{*}, L_{m}^{*}, k_{m}^{*}, m, S_{m}^{*}\right)$ \\
\hline \multirow{3}{*}{-2} & 1 & 28 & 22.4 & 172.3 & $1.266(64)$ & 256.8 & 157 & .897 & 7747.1 \\
& 2 & 28 & 22.4 & 172.3 & $1.399(66)$ & 404.4 & 124 & .919 & 7728.1 \\
& 3 & 28 & 22.4 & 172.3 & $1.490(67)$ & 510.8 & 104 & .932 & 7872.9 \\
-.5 & 1 & 21 & 57.4 & 101.9 & $1.302(50)$ & 241.0 & 148 & .904 & 7539.2 \\
& 2 & 21 & 57.4 & 101.9 & $1.436(52)$ & 377.7 & 116 & .924 & 7477.2 \\
& 3 & 21 & 57.4 & 101.9 & $1.527(53)$ & 475.6 & 97 & .937 & 7584.9 \\
-.8 & 1 & 21 & 57.4 & 43.1 & $1.367(51)$ & 214.5 & 131 & .914 & 7281.0 \\
& 2 & 21 & 57.4 & 43.1 & $1.504(53)$ & 331.3 & 101 & .934 & 7145.4 \\
& 3 & 21 & 57.4 & 43.1 & $1.598(54)$ & 413.0 & 84 & .945 & 7187.8 \\
-1.0 & 1 & 21 & 57.4 & 3.8 & $1.423(52)$ & 193.6 & 119 & .923 & 7088.8 \\
& 2 & 21 & 57.4 & 3.8 & $1.565(54)$ & 294.2 & 90 & .941 & 6894.7 \\
& 3 & 21 & 57.4 & 3.8 & $1.661(55)$ & 362.3 & 74 & .952 & 6884.4 \\
\hline
\end{tabular}

${ }^{\mathrm{a}} \mathrm{SL}$ denotes service level, which is measured by $1-P_{r}(X-R)$.

Table 4.

Allocation of the total annual cost for each case of $\tau$.

\begin{tabular}{|c|c|c|c|c|c|c|c|c|}
\hline \multirow{3}{*}{$\tau$} & \multirow{2}{*}{\multicolumn{3}{|c|}{ Non-integrated model }} & \multicolumn{5}{|c|}{ Integrated model } \\
\hline & & & & \multicolumn{2}{|r|}{ Buyer } & \multicolumn{2}{|r|}{ Vendor } & \multirow{2}{*}{$J T C$} \\
\hline & $T C_{b}$ & $T C_{v}$ & JTC & $T C_{b}$ & Allocated annual cost & $T C_{v}$ & Allocated annual cost & \\
\hline-.2 & 3313.5 & 4421.0 & 7734.5 & 3317.6 & 3310.8 & 4410.5 & 4417.3 & 7728.1 \\
\hline-.5 & 3046.3 & 4443.6 & 7489.9 & 3055.6 & 3041.1 & 4421.6 & 4436.1 & 7477.2 \\
\hline-.8 & 2665.5 & 4519.8 & 7185.3 & 2692.2 & 2650.7 & 4453.2 & 4494.7 & 7145.4 \\
\hline-1.0 & 2347.6 & 4546.8 & 6894.4 & 2353.8 & 2344.2 & 4530.6 & 4540.2 & 6884.4 \\
\hline Traditional model & 3454.7 & 5157.3 & 8612.0 & 3484.7 & 3428.5 & 5061.9 & 5118.1 & 8546.6 \\
\hline
\end{tabular}

ing various $\tau$ values with the cost of the traditional integrated model involving lead time reduction. We find that setup cost, lead time and ordering cost reductions simultaneously decrease the cost of both the vendor and the buyer.

\section{Conclusion}

Independent decision made by a buyer or a vendor usually does not result in global optimum. For this reason, business cooperation among channel members is vital to a supply chain's performance. In this study, we develop an integrated business vendor-buyer imperfect inventory model where setup cost and lead time reductions are considered in the vendor-buyer partnership. Our model assumes complete and partial information about lead-time demand distribution. Our results show that when lead time and ordering cost reductions are closely correlated, an integrated policy with higher frequency of deliveries, smaller lot size and shorter lead time is more desirable. To entice collaboration, the setup cost and lead time reductions must result in cost saving for both the vendor and the buyer.

\section{REFERENCES}

Affisco, J. F., Paknejad, M. J., \& Nasri, F. (1988). Investing in setup cost reduction in the joint economic lot size model. Proceedings of the Decision Sciences Institute, 1126-1129.

Affisco, J. F., Paknejad, M. J., \& Nasri, F. (2002). Quality improvement and setup cost reduction in the joint economic lot size model. European Journal of Operational Research, 142, 497-508. http://dx.doi.org/10.1016/S0377-2217(01)00308-3

Ballou, R. H. (2004). Business Logistics/Supply Chain Management.
Upper Saddle River: Pearson Education.

Banerjee, A. (1986). A joint economic-lot-size model for purchaser and vendor. Decision Sciences, 17, 292-311. http://dx.doi.org/10.1111/j.1540-5915.1986.tb00228.x

Ben-Daya, M., \& Raouf, A. (1994). Inventory models involving lead time as a decision variable. Journal of the Operational Research Society, 45, 579-582.

Ben-Daya, M., \& Hariga, M. (2003). Lead-time reduction in a stochastic inventory system with learning consideration, International Journal of Production Research, 41, 571-579. http://dx.doi.org/10.1080/00207540210158807

Chen, C. K., Chang, H. C., \& Ouyang, L. Y. (2001). A continuous review inventory model with ordering cost dependent on lead time. International Journal of Information and Management Sciences, 12, 113.

Chung, K. J., \& Huang, Y. F. (2006). Retailer's optimal cycle times in the EOQ model with imperfect quality and a permissible credit period. Quality and Quantity, 40, 59-77.

http://dx.doi.org/10.1007/s11135-005-5356-z

Goyal, S. K. (1976). An integrated inventory model for a single supplier-single customer problem. International Journal of Production Research, 15, 107-111. http://dx.doi.org/10.1080/00207547708943107

Goyal, S. K. (1988). A joint economic-lot-size model for purchaser and vendor: A comment. Decision Sciences, 19, 236-241. http://dx.doi.org/10.1111/j.1540-5915.1988.tb00264.x

Goyal, S. K., Huang, C. K., \& Chen, K. C. (2003). A simple integrated production policy of an imperfect item for vendor and buyer. Production Planning \& Control, 14, 596- 602. http://dx.doi.org/10.1080/09537280310001626188

Ha, D. \& Kim, S. L. (2003). A JIT lot-splitting model for supply chain management: Enhancing buyer-supplier linkage. International Journal of Production Economics, 86, 1-10. http://dx.doi.org/10.1016/S0925-5273(03)00006-9

Hariga, M. (1999). A stochastic inventory model with lead time and lot 
size interaction. Production Planning and Control, 10, 434-438. http://dx.doi.org/10.1080/095372899232957

Hill, R. M. (1997). The single-vendor single-buyer integrated production inventory model with a generalized policy. European Journal of Operational Research, 97, 493-499.

http://dx.doi.org/10.1016/S0377-2217(96)00267-6

Huang, C. K. (2004). An optimal policy for a single-vendor singlebuyer integrated production-inventory problem with process unreliability consideration. International Journal of Production Economics, 91, 91-98. http://dx.doi.org/10.1016/S0925-5273(03)00220-2

Lu, L. (1995). A one-vendor multi-buyer integrated inventory model. European Journal of Operational Research, 81, 312-323. http://dx.doi.org/10.1016/0377-2217(93)E0253-T

Nasri, F., Paknejad, M. J., \& Affisco, J. F. (1991). Simultaneous investment in setup cost and order cost reduction in the joint economic lot size model. Proceedings of the Northeast Decision Sciences Institute, 263-267.

Ouyang, L. Y., Yeh, N. C., \& Wu, K. S. (1996). Mixture inventory model with backorders and lost sales for variable lead time. Journal of the Operational Research Society, 47, 829-832.

Ouyang, L. Y., Wu, K. S., \& Ho, C. H. (2004). Integrated vendor-buyer cooperative model with stochastic demand in controllable lead time.
International Journal of Production Economics, 92, 255-266.

http://dx.doi.org/10.1016/j.ijpe.2003.10.016

Pan, J. C. H., \& Yang, J. S. (2002). A study of an integrated inventory model with controllable lead time. International Journal of Production Research, 40, 1263-1273.

http://dx.doi.org/10.1080/00207540110105680

Papachristos, S., \& Konstantaras, I. (2006). Economic ordering quantity models for items with imperfect quality. International Journal of Production Economics, 100, 148-154. http://dx.doi.org/10.1016/j.ijpe.2004.11.004

Porteus, E. L. (1986). Optimal lot sizing, process quality improvement and setup cost reduction. Operations Research, 34, 137-144.

http://dx.doi.org/10.1287/opre.34.1.137

Salameh, M. K., \& Jaber, M. Y. (2000). Economic production quantity model for items with imperfect quality. International Journal of Production Economics, 64, 59-64.

http://dx.doi.org/10.1016/S0925-5273(99)00044-4

Yang, P. C. \& Wee, H. M. (2000). Economic ordering policy of deteriorated item for vendor and buyer: An integrated approach. Production Planning and Control, 11, 474-480. http://dx.doi.org/10.1080/09537280050051979 